\title{
O TEMPO E O MUNDO: DEFESA DE UMA HISTÓRIA PLANETÁRIA
}

\section{Gustavo Velloso*}

Universidade de São Paulo

São Paulo - São Paulo - Brasil

Resenha do livro: GRUZINSKI, Serge. As quatro partes do mundo: história de uma mundialização. Tradução de Cleonice Paes Barreto Mourão e Consuelo Fortes Santiago. Belo Horizonte: Editora UFMG; São Paulo: Edusp, 2014.

A edição brasileira do livro As quatro partes do mundo: história de uma mundialização (no original: Les quatre parties du monde: histoire d'une mondialisation) do historiador francês Serge Gruzinski, por associação da Editora UFMG com a Edusp, chega em boa hora. A aceleração do fluxo de pessoas, mercadorias e informações em um contexto de crise sistêmica do capitalismo, o surgimento de novas tensões políticas em fronteiras nacionais de todo o mundo, bem como a austeridade das políticas de imigração nos países centrais (e os diferentes tipos de reação a elas) são fenômenos que têm exigido dos historiadores novos esclarecimentos sobre a dinâmica das transformações

\footnotetext{
* Mestre em História Social pela Faculdade de Filosofia, Letras e Ciências Humanas. E-mails: gustavo.velloso@usp.br; gustavo.velloso@hotmail.com.
} 
originadas mundialmente no contexto das navegações marítimas do século XVI e ainda hoje processadas. A obra de Gruzinski representa um passo significativo nessa direção.

\section{I}

A mundialização a que se refere o subtítulo é aquela associada ao poderio da monarquia ibérica - expressão empregada pelo autor sempre na forma singular, realçando a época de unidade das coroas portuguesa e espanhola, entre os anos 1580 e 1640. Todavia, sua análise não se limita aos quadros cronológicos dessa união, pois mobiliza materiais e informações que dizem respeito a outros anos, incluindo anos recentes e contemporâneos à primeira edição do texto (2004). Gruzinski principia, em seu prólogo, chamando atenção para a repercussão que houve da notícia do ataque às torres gêmeas norte-americanas, em 2001, em um restaurante situado em Buenos Aires, cujo garçom lamentou não ter apostado na combinação numérica referente àquele fato, e nas ruas de Belém do Pará, onde a multidão local transformou sua tradicional procissão à Virgem de Nazaré em um verdadeiro protesto contra o atentado. E encerra o livro, em epílogo, problematizando a ideologia contida nas produções cinematográficas da globalização hollywoodiana. Com isso, destaca a multiplicidade e a sincronia dos diferentes tempos históricos, as mestiçagens e a espontaneidade das reações travadas contra as dominações mundiais de ontem e de hoje.

O autor cuida, no entanto, para que o leitor não identifique na mundialização ibérica a origem imediata da mundialização americana, pois se trataria antes de um antecedente remoto. A razão do paralelo consiste em "mostrar que a história permanece uma maravilhosa caixa de ferramentas para compreender o que está em jogo, há vários séculos, entre ocidentalização, mestiçagem e mundialização" (p. 23). Em outras palavras, a história da monarquia ibérica serve-nos como um admirável "teatro de observação" (p. 45) do mundo presente. Comprometido criticamente com o seu próprio tempo, recusando instrumentalizar a disciplina histórica apenas para a mera fruição erudita, Gruzinski não deixa por isso de respeitar as particularidades e a historicidade do seu objeto principal, isto é, o estreitamento dos laços entre as "quatro partes do mundo", operado sob o domínio da monarquia católica durante os séculos XVI e XVII. 
A obra se divide em quatro partes. Na primeira ("A mundialização ibérica", capítulos 1 a 3), o autor precisa os contornos da categoria "mundialização", em uma conceituação intimamente associada a uma certa noção de "modernidade". No seu entendimento, "mundialização" se refere à escala planetária dos horizontes de atuação e às interconexões humanas, materiais e simbólicas que se construíram sob o marco da dominação colonial da monarquia católica nos continentes europeu, africano, asiático e americano. A modernidade desse processo consiste no fato de que teria então aflorado nos diferentes agentes históricos "um estado de espírito, uma sensibilidade, um saber sobre o mundo nascidos da confrontação de uma dominação de visão planetária com outras sociedades e outras civilizações" (p. 32). Uma modernidade marcada pela geração de mediadores sociais e espaços intermediários de convergência do "local" com o "global", além de choques culturais, dominação, adaptações, mestiçagem e resistências.

A repercussão, no México, de notícias como a da morte de um rei francês em 1610, o interesse de um escritor mestiço da Nova Espanha pelas coisas do Japão, os deslocamentos de homens e mulheres pelos mares, a busca e o translado de relíquias provenientes dos mais exóticos lugares, a difusão das línguas europeias, a circulação transoceânica de livros que muitas vezes propagandeavam saberes adquiridos por viajantes nas fronteiras do mercado mundial, o alargamento dos limites geográficos, o compartilhamento global de novos hábitos e formas de consumo: eis os indícios daquilo que Gruzinski caracterizou como "mobilização". Esse conceito, emprestado do filósofo alemão Peter Sloterdijk, permite ao autor superar o caráter mecânico e eurocêntrico do vocábulo "expansão", à medida que considera, além do mero deslocamento territorial, a expressão dos movimentos subjetivos, entusiasmos e precipitações de seres humanos, coisas materiais e saberes cambiados entre os hemisférios.

Na segunda parte do livro ("A cadeia dos mundos", capítulos 4 a 6) encontramos o exame detido e aprofundado das conexões entre os continentes, bem como os choques e o caráter mestiço das formações sociais e culturais resultantes daquele movimento. Focalizando inicialmente a Cidade do México - "onde se modelam os liames entre as quatro partes do mundo", cenário privilegiado "de coexistência, de afrontamentos e de mestiçagens" (p. 99) -, o autor realiza uma breve incursão sobre o mundo do trabalho para enfatizar o papel da tradição artesanal indígena no favorecimento da absorção pelos nativos dos ofícios europeus. Em seguida, narra a mestiçagem linguística 
operada no interior dos obrajes e dos ateliês, graças à atuação de mediadores sociais como espanhóis falantes do náuatle, religiosos, elites indígenas hispanizadas, mestiços e índios trabalhadores manuais. A heterogeneidade étnica e a porosidade social não foram capazes de evitar, no entanto, as "vias tortuosas" da mudança. Ora, à maior parte dos nativos foram vedados os meios de participação na estrutura monárquica que não fosse pelo oferecimento de força de trabalho. E a nova plebe constituída no interior das grandes cidades se envolveu, por vezes, em revoltas e motins de grande dimensão, contra o fisco e/ou mudanças na organização da monarquia.

No quadro da mundialização/mobilização ibérica, argumenta Gruzinski, a visão de mundo que orienta os esforços humanos vai progressivamente perdendo sua configuração "estritamente europeia para se tornar ocidental" (p. 126). Em outras palavras, a Europa deixa de ser o núcleo exclusivo da monarquia para se somar (na condição de dominante, não resta dúvida) a tantos outros centros globais então em franco crescimento: "[Pode-se] perguntar se a capacidade de multiplicar as centralidades meio reais, meio virtuais não é uma das molas da mundialização ibérica" (p. 127). Cidade do México, Lima, Potosí e Goa aparecem como espacialidades mestiças que sintetizam em seus interiores a totalidade dos nexos que unificam o planeta debaixo do poder dos reis Felipes, pois abrigam redes humanas, mercantis, de notícias, livros e espetáculos. Nela se evocam lembranças da África, fascinam-se pelos objetos e fábulas da Ásia, colam-se imaginários provenientes de toda parte, enfim, entrelaçam-se perspectivas de mundialização com referenciais advindos dos mais diferentes ideários pré-hispânicos.

Como uma ponte que atravessa de uma única vez todos os oceanos, o caráter compósito dessas ligações era "ao mesmo tempo físico, material, psicológico e conceitual" (p. 156). Instituições, práticas e crenças foram transferidas juntamente aos seus representantes para materializar o catolicismo no mundo extra europeu, mas não sem antes sofrer transformações e ajustes conforme as especificidades locais de cada região. Histórias, trajetórias, ritmos de vida, memórias e riquezas, à medida que sincronizados, fizeram-se modernos.

Os agentes privilegiados da mundialização são objeto da terceira parte da obra ("As coisas do mundo", capítulos 7 a 11). Homens como o médico Garcia de Orta e o dominicano Gaspar da Cruz, ambos portugueses, funcionários da Igreja ou da Coroa, assim como administradores, militares, cosmógrafos, engenheiros e literatos, instrumentalizaram suas experiências vivenciadas em locais como Goa e Nova Espanha para cumprir objetivos ao mesmo tempo práticos e políticos. As informações e os conhecimentos feitos circular por esses hombres expertos, de um lado, serviam como denúncia da 
idolatria e dos maus costumes das diversas castas de gentio, e fortaleciam os poderes real e eclesiástico sobre as localidades fronteiriças. Unir os mundos, diz-nos o autor, era antes de mais nada "fazê-los comunicar" (p. 235). Inventariando as características das sociedades e da natureza (americanas, africanas e asiáticas), recolhendo informações sobre as culturas humanas, as condições geográficas, os animais, as plantas, as religiões e as medicinas locais, por exemplo, os saberes se convertiam em verdadeiras ferramentas de poder.

Com a autoridade dos escritores clássicos, ademais, os experts rivalizavam entre si pela defesa da credibilidade da própria experiência e se esforçavam para interpretar a diversidade das fontes, das escritas e das histórias indígenas com as quais deparavam. É certo que esse movimento demonstra ter existido um certo grau de receptividade frente aos "outros mundos", mas havia limites quase nunca transpostos, expressos sobremaneira no tom crítico com o qual tais observadores se posicionavam diante daquelas outras realidades. Sua tarefa era dupla, "pois lhes é preciso tanto conectar-se com o passado autóctone, quanto com a história cristã e europeia" (p. 280). Eram, acima de tudo, servidores da monarquia, em cujo interior se situavam e para a qual dominação direcionavam primordialmente os seus esforços e a sua sempre enfatizada fidelidade. Especialmente quando se tratasse de elites católicas, à maneira de gente como Martín Ignacio de Loyola, Rodrigo de Vivero, Salvador Correia de Sá e Benevides e os poetas Bernardo de Balbuena e Luís de Camões.

Gruzinski delineia com perfeição as mestiçagens, acomodações e resistências indígenas travadas no contexto da colonização ibérica, trabalhando com a justa dosagem entre o apontamento desse tipo de fenômeno e o reconhecimento do processo de dominação mundial levado a cabo concretamente pela monarquia. Na verdade, trata-se para o autor de esferas indistintas, pois a perspectiva metodológica que adota é a da totalidade, distanciando-se da tendência historiográfica contemporânea para descrever "resistências" desconexas de processos históricos mais amplos, isto é, concretos ou totais. A quarta e última parte do livro ("A esfera de cristal", capítulos 12 a 16), tem por princípio enfatizar os filtros e bloqueios aos cruzamentos, as impermeabilidades sociais da realidade observada e demonstrar que, afinal: "Toda mestiçagem tem limites" (p. 352). Os objetos nativos, quando absorvidos pelo universo europeu, modificavam-se para satisfazer o gosto e o interesse da sociedade europeia. A arte indígena, tornada cristã e/ou inserida nos circuitos modernos de valorização, era neutralizada e reelaborada com traços e formas de matriz europeia, transformando-se em arte ocidental. "A mundialização ibérica mestiça-se ocidentalizando-se, e ocidentaliza-se mestiçando-se" (p. 349). Os pintores europeus que viveram 
na Nova Espanha fizeram questão de destacar a fidelidade à tradição europeia em suas telas, assim como as elites urbanas (por vezes até mesmo as indígenas) procuraram convencer de que foram europeizadas por meio de suas produções, o que não excluiria uma certa apropriação criativa dos recursos locais. O latim, a gramática e os emblemas europeus teriam sido apenas pontualmente tocados pelas influências léxicas indígenas, ao menos no que tange àquele momento histórico particular. $\mathrm{O}$ aristotelismo - "a arma de uma fortaleza letrada que ataca em todas as direções" (p. 434) -percorreu os continentes e permaneceu grosso modo impenetrável pelas filosofias e sistemas de pensamento locais, por mais admiráveis que estes tenham parecido a determinados observadores estrangeiros.

A análise toda culmina ainda em uma nova demarcação conceitual, que consiste na distinção entre "globalização" e "ocidentalização". Como uma "águia de duas cabeças", a mundialização ibérica gestou e abraçou esses dois processos simultâneos, na prática indissociáveis, mas ainda assim com dimensões e escalas diferenciadas. De um lado, a globalização, "fundamentalmente política" (p. 426), diria respeito à projeção para o exterior dos instrumentos intelectuais e comunicativos europeus, ignorando as temporalidades sociais distintas e "cuidando para que nada de essencial fosse contaminado pelo exterior" (p. 425). De outro, a ocidentalização se manifestaria no caminho da dominação colonial propriamente dita, esta sim amplamente permeada tanto pela mestiçagem quanto pela aculturação.

\section{III}

O autor se posiciona favoravelmente à perspectiva das connected histories, conforme proposta pelo historiador indiano Sanjay Subrahmanyam. Na sua interpretação, "trata-se de apreender ou restabelecer as conexões surgidas entre os mundos e as sociedades, um pouco à maneira de um eletricista que viria reparar o que o tempo e os historiadores desuniram" (p. 45). E, uma vez assumida essa ótica, posiciona-se de maneira crítica frente às principais tendências historiográficas hoje vigentes. O pós-modernismo, ou "retóricas da alteridade", para ele, ignora as continuidades e correspondências concretas entre os seres e as sociedades, e com isso se soma à chamada micro-história na sua incapacidade de alargamento dos horizontes de observação. A história comparada lhe parece reduzir-se às aproximações e ser excessivamente carregada de pressupostos vazios. Sobre a world history, apesar do importante legado que deixou para o olhar sobre a transposição dos oceanos, julga ser ainda permeada pelo etnocentrismo, sacrificando a profundidade das si- 
tuações particulares e se mantendo demasiadamente presa aos horizontes próprios da Europa ocidental. A este defeito tampouco fugiriam os cultural studies, os subalternal studies e os postcolonial studies estadunidenses da década de 1980. Ao marxismo, não dedicou mais que uma tímida nota (p. 464, nota 97), ainda que simpática, apontando a existência de uma releitura de Marx aplicada ao fenômeno da mundialização. O alvo principal de Gruzinski, todavia, contra o qual direcionou com maior vigor o potencial crítico do seu estudo, é o reducionismo das histórias nacionais em suas diferentes manifestações. Contra estas, não hesitou em reconhecer, ademais, a contribuição de pesquisadores de renome, como Fernand Braudel e Immanuel Wallerstein, cujas obras abriram as vias para o reconhecimento de que a história da época moderna é a história das múltiplas conexões entre o local e o global; não é uma história nacional, mas planetária.

Os méritos de "As quatro partes do mundo" ultrapassam as próprias conclusões do livro e o fato de se travar ali um debate historiográfico amplo. Sua maneira de dispor e mobilizar as fontes primárias é igualmente digna de reconhecimento. Gruzinski soube equilibrar com perfeição e harmonia, de um lado, a erudição empírica e, de outro, o ímpeto pelo rigor conceitual e pelas interpretações de maior alcance. Apresenta um olhar permanentemente atento ao detalhamento dos materiais examinados, que comportam desde crônicas, relações e outros testemunhos escritos, até a poesia, os quadros, tratados, objetos de museu, códices, planos, painéis, biombos, inscrições, vasos, gravuras e afrescos. De leitura fluente e agradável, a edição presente conta ainda com a reprodução de uma iconografia cuidadosamente selecionada e distribuída entre os capítulos, grande parte dela problematizada e discutida no próprio texto onde se coloca.

Além disso, do ponto de vista metodológico, o leitor encontrará uma visão rica de processo histórico e uma sensibilidade extraordinária para o conflito. Sua narrativa não é a de uma estrutura estática, mas sim de uma totalidade em permanente formação e mudança, em processo contínuo (mas não linear), o que fica ilustrado na repetição do sufixo indicativo de ação nos seus mais importantes conceitos e categorias: mobilização, mundialização, globalização, ocidentalização. A continuidade dos referidos processos não exclui que eles fossem também, ao mesmo tempo, pluridimensionais e repletos de tensões. Assim, o fenômeno da mestiçagem do qual dão conta os numerosos eventos levantados por Gruzinski (tocantes a cada um dos quatro continentes) não seria menos que a ebulição dos complexos antagonismos entre expectativas, lugares e papéis sociais gerados no seio da mundialização ibérica. Expressava, pois, não qualquer tipo de harmonia ou conformidade 
social entre dominados e dominadores, mas as contradições inerentes ao processo mesmo de dominação, que envolviam toda a variedade de agentes governados pela monarquia, fossem eles europeus, nativos ou crioulos.

É verdade, porém, que de uma obra que se apresenta como a "história de uma mundialização" poderíamos esperar uma incursão mais aprofundada sobre determinados domínios que parecem-nos tão fundamentais para a compreensão da época quanto aqueles dos quais tratou Gruzinski com efetivo zelo. Por exemplo, não há mais que breves pinceladas sobre alguns dos diferentes regimes de exploração do trabalho compulsório em maior ou menor medida relacionados àquela mundialização (escravidão, encomienda, mita, administração particular, repartimiento, assalariamento, "segunda servidão" etc.). Ou então se poderia alegar que, entre todas as áreas americanas tocadas pela monarquia dos Felipes, o autor claramente privilegiou a Nova Espanha em suas remissões (ofuscando territórios de menor relevância econômica para os reis ibéricos, onde as conexões globais eram decerto menos visíveis), o que pode ser explicado pela maior familiaridade com os materiais empíricos que lhe correspondem, dada sua experiência anterior com as investigações daquela região.

Mas o que torna as teses de Gruzinski provocantes é justamente o fato de o autor tê-las apresentado como propostas abertas, porventura incompletas, dispostas à complementação e ao aperfeiçoamento. Abertura esta que, por fim, se estende para o âmbito do tempo imediato, sendo impressionante a atualidade do livro (editado primeiramente em 2004, já o dissemos) em um estágio da globalização em que, se ainda não presenciamos um novo ataque a edifícios norte-americanos, temos sido alarmados diante de explosões e fuzilamentos em lugares como a sede de um jornal, um teatro e as proximidades de um estádio de futebol, todos na França. Para não falar, obviamente, nas irrupções menos midiáticas sobre Gaza e Iêmen, sobre os territórios dos Mapuche e dos Guarani Kaiowá ou, quem sabe, sobre a Rocinha e o Morro do Alemão. 